This item was submitted to Loughborough's Research Repository by the author.

Items in Figshare are protected by copyright, with all rights reserved, unless otherwise indicated.

\title{
Classification and selection of tools for quality knowledge management
}

PLEASE CITE THE PUBLISHED VERSION

http://dx.doi.org/10.1007/s11219-010-9121-8

PUBLISHER

(C) Springer Verlag

VERSION

SMUR (Submitted Manuscript Under Review)

LICENCE

CC BY-NC-ND 4.0

REPOSITORY RECORD

Holland, Suzi, and Ray Dawson. 2019. "Classification and Selection of Tools for Quality Knowledge Management". figshare. https://hdl.handle.net/2134/14759. 
This item was submitted to Loughborough's Institutional Repository (https://dspace.lboro.ac.uk/) by the author and is made available under the following Creative Commons Licence conditions.

\section{creative
commons}

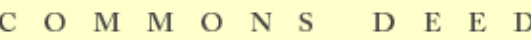

Attribution-NonCommercial-NoDerivs 2.5

You are free:

- to copy, distribute, display, and perform the work

Under the following conditions:

Attribution. You must attribute the work in the manner specified b the author or licensor.

Noncommercial. You may not use this work for commercial purposes.

No Derivative Works. You may not alter, transform, or build upon this work.

- For any reuse or distribution, you must make clear to others the license terms of this work.

- Any of these conditions can be waived if you get permission from the copyright holder.

Your fair use and other rights are in no way affected by the above.

This is a human-readable summary of the Leqal Code (the full license).

\section{Disclaimer 만}

For the full text of this licence, please go to: http://creativecommons.org/licenses/by-nc-nd/2.5/ 


\title{
Classification and Selection of Tools for Quality Knowledge Management
}

\author{
Suzi Holland, Ray Dawson \\ Computer Science Department, Loughborough University, Loughborough, UK \\ Email: S.J.Holland@lboro.ac.uk
}

\begin{abstract}
Knowledge managers need to select which knowledge management tool to use for any given problem and problem environment. The graphical tool, named the "House of Knowledge Management Tool Selection" is proposed, based on the House of Quality Matrix used in the quality function deployment methodology. A simple case study is described that acts as a proof of concept to show the House of Knowledge Management Tool Selection can systematically evaluate potential tools to solve a knowledge management problem.

To help identify the tools to populate the house, an examination was undertaken of how knowledge management tools had previously been listed and classified, but these existing classifications were found to be of little help. No classification existed that categorised the tools in terms of the knowledge problems they helped resolve, yet this classification would seem more useful for knowledge managers.

To meet this need, knowledge problems were divided into ten subtypes and the knowledge management tools where then categorised according to their effectiveness at solving each subtype. This new classification was flexible enough to include all types of knowledge management tools and could also change with each problem environment. It was found to give a greater understanding of the knowledge management tools in the context of a particular knowledge problem and it could therefore help populate the house tool.

The House of Knowledge Management Tool Selection is a promising development of a tool that should be able to become an essential part of a manager's decision making toolkit.
\end{abstract}

Keywords: Knowledge management tools, Knowledge problems, Tool selection, Tool classification

\section{Introduction}

Dawson (2007) reported in his keynote paper at Software Quality Management 2007 that knowledge management initiatives do not always give the results that were expected. Various issues and barriers have been uncovered that stand in the way of successful implementation of knowledge management solutions. To overcome this, Dawson (2007) proposed a ten step methodology for implementing a successful knowledge management solution. This paper looks at the second of those ten steps 'Finding a knowledge management solution in the context of the problem' for which Dawson's methodology did not indicate any means that could be used to carry out the step. This paper proposes a tool that will aid the business manager in finding a knowledge management solution for an identified problem that can be adapted to any particular context. This tool can then be the basis of a systematic methodology to find a suitable knowledge management tool giving a quality solution in the context of the problem.

The tool would need to be simple to use, such that managers in many different disciplines could use it, and flexible such that they could use the tool on a wide variety of problems. For this purpose it was decided to examine potential diagrammatic tools that could be implemented on a drawing package or spreadsheet as these are familiar basic technologies that managers use. 


\section{The Starting Point for the Tool Development}

A spreadsheet solution was examined but it was found that, in order to accommodate all the information required, the solution stretched over several pages making it hard for the manager to be able to both manipulate and visualise the results.

The 'House of Quality Matrix’ is part of Quality Function Deployment (QFD Online 2007), a technique for aiding managers in decision making when choosing product options. This matrix was originally designed to investigate a single product but to take into account the many different influences on the manufacturing of the product, especially the customer's view of the product. The end result is to recommend the choice of a product that balances the various influences and highlights the degree of difficulty in resolving some of the issues, some of which may not have previously been considered. The same approach could be applied to choosing a knowledge management tool to solve a knowledge problem, by investigating all areas that may affect the successful implementation of the tool. This gives the manager the opportunity to take any mitigating action against them.

The House of Quality Matrix is designed on a spreadsheet and due to its compact nature it is possible to fit it onto one page, making it easier for managers to visualise the problem and results. In order to achieve this, the house is divided into six different areas. Some of these areas can be filled in independently, without reference to the complete matrix and then the results transferred to the main grid. The six different areas represent the different influences that affect the final product. They are:

- Left Hand Extension: The customer requirements are placed here to represent what the customer wants form the product.

- The planning matrix: This represents the competitors' products from the customers view and is positioned in an extension on the right hand side of the house.

- Technical requirements: The 'How' section shows how the product will meet the customers' needs and is positioned in the top floor of the house.

- Inter-relationships: This is the middle area of the grid, the main body of the house, and shows how well the product meets the customer's needs.

- Conflicts: This focuses on the conflict between the technical requirements and is in the roof of the house.

- $\quad$ Targets: This area gives the results of the planning matrix and is situated in the basement. 


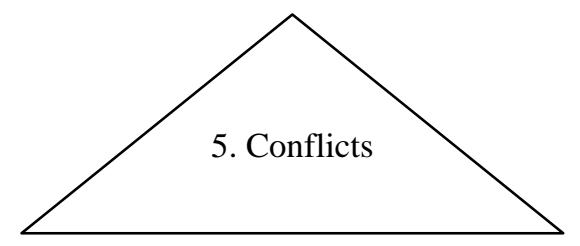

3. Technical Requirements
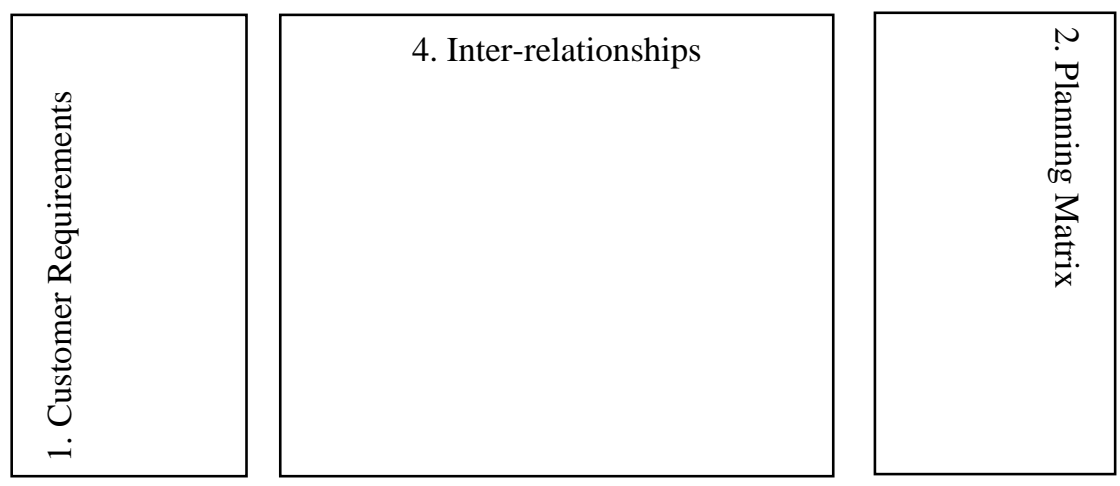

\section{Targets}

Figure1: House of Quality

Filling in the House of Quality matrix can take a lot of time (Logan and Radcliffe 2007) and can come across as quite complicated when working out the weightings. These are two obstacles to overcome when transforming this into a useful knowledge management tool.

It is proposed that the tool for Knowledge Management, to be called the 'House of Knowledge Management Tool Selection' (HoKMTS) should be based on the House of Quality. A knowledge management solution requires tailoring the areas of the house to suit the needs of solving the knowledge problem. These sections will allow the manager to see the many aspects of implementing a solution that may otherwise have been overlooked and see how they may affect the knowledge management tools the manager could employ to solve the problem. All the possible tools and techniques that the manager is considering will be accommodated as part of the grid. As the HoKMTS is designed on a spreadsheet format it will be possible to run 'what if' scenarios as well as being able to show results as graphs.

\section{The House of Knowledge Management Tool Selection}

To implement the new house it is necessary to identify the areas that are required to solve the knowledge problem. Then, they can be incorporated into the house.

In order to find the successful knowledge management solution the problem itself needs to be broken down into separate components. These components need to focus on the knowledge management processes that will occur as well as considering any business drivers that are seen as critical. The problem requirements are in one section of the house. The tools and knowledge management techniques that are being considered to solve the problem will also need their own section in the house. The house needs to offer the manager the ability to view all the tools being considered in one section of the house so that it is easy to compare the results of all of the tools. The relationships between the tools and the problems and a results area will be required by the manager and this will occupy a third section of the house. Investigation into knowledge management initiatives has shown that there are a number of barriers to successful implementation 
of solutions that are specific to knowledge management (Du Plessis 2008) and as such a barriers section will be used to represent these and show their effects on the tools. A final section of the house is one that can show if tools could be used together to give a more complete solution to the problem.

The areas of the House of Quality will be used in the HoKMTS as follows:

- $\quad$ The left hand extension will become the problem requirement section. This area will hold the breakdown of the knowledge problem being dealt with.

- The right hand section that held the planning matrix is not being incorporated into the HoKMTS at present.

- The top floor will become the knowledge tool or technique area. This will host the list of possible tools that could be used to solve the knowledge management problem.

- The main body of the house will give the relationships between the tools and the problems and totals of the weightings. This is the main output section of the house

- The roof area remains and is used to show the connections between the tools, showing which can be used together.

- The basement area becomes the barrier basement showing the effect of the barriers on each proposed tool.

Figure 2 shows the position of the different areas. Starting from the bottom, there are the barriers, the section above holds the inter-relationships between the tools and the problems as well as the results section with the tools above that. The annex on the left hosts the problem requirements and the roof is the multiple tool selection space.

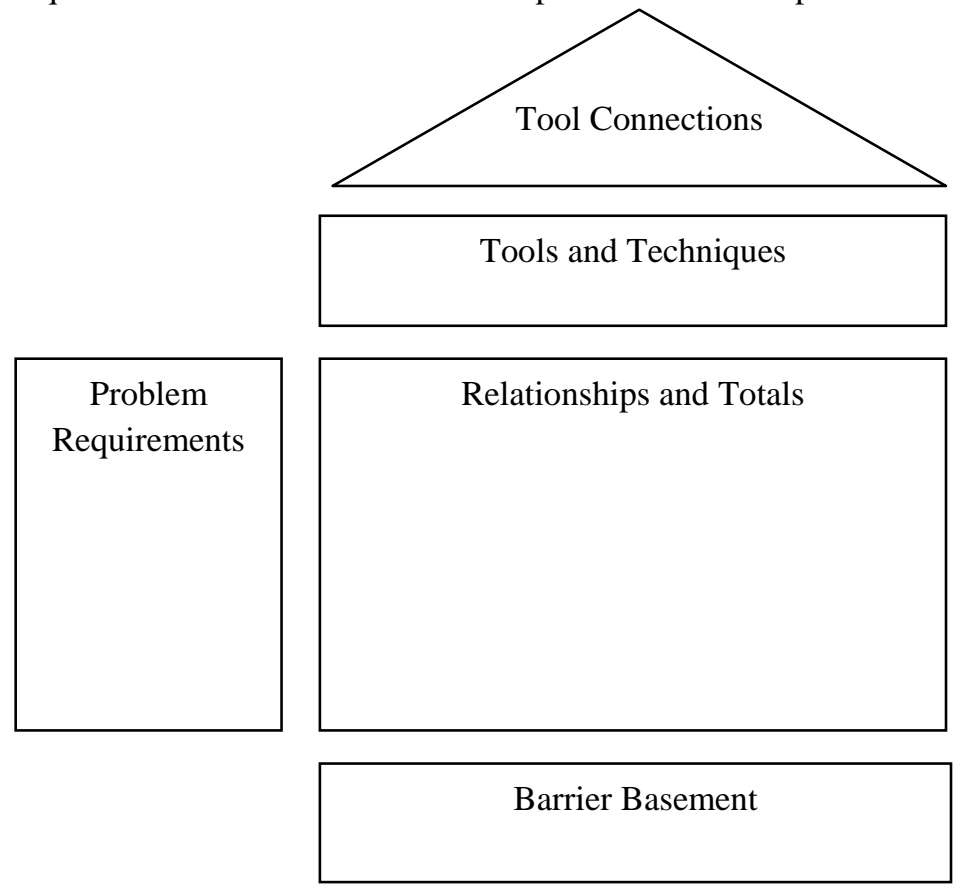

Figure 2: The House of Knowledge Management Tool Selection.

\subsection{Problem Requirements Area (house extension)}

The problem is broken down to look at specific features that would be associated with a knowledge management problem. The headings in this section would remain the same for all problems that would be looked at, making them permanent features of the house. This would lead to the managers being able to systematically evaluate all problems in terms of recognised features of knowledge management. Keeping the headings the same also ensures that managers will look thoroughly at the entire problem and not just the obvious, ensuring that better solutions are reached. 
The different parts of the problem requirements are then rated to show how important they are in relation to solving the problem. A rating scale from 0 to 5 is used to rate this. 0 represents that the problem being solved does not contain this type of knowledge problem, while 5 suggest that it is a main part of the problem. This scale was selected as it was found to be easy to handle and gives a sufficient number of levels to distinguish cases. Indeed, in practice many of the values here will be 0 or 5 indicating that these aspects of knowledge management are either not relevant or completely relevant. It is also apparent that some of the problem breakdowns when rated will actually have an adverse overall effect on the problem. Thus for a section of the problem on 'cost' a score of 0 for a tool would imply low cost and a score of 5 would imply high cost for that tool. This demonstrates that some of the problem breakdowns will have a positive effect on the overall success of that solution while other parts of the problem breakdown, using this scaling method, will have a negative effect on the success of the solution.

\subsection{Technique or Tool Area (top floor of the house)}

The technique and tool section represents the knowledge management solutions that are being investigated and can be broken down into IT tools and those solutions that are non IT. The number of tools shown in the grid would depend on the problem being looked at and the sort of solution required. The user should include all KM tools that could conceivably be relevant to allow for solutions to be derived that may otherwise not have been considered. Allowing managers to add their own columns to this section as the need arises keeps the house flexible in its uses.

\subsection{Relationship and Totals (main body of the house)}

The different tools under investigation are represented by the columns of the matrix with the problem broken down into components being the horizontal rows of the matrix. These components are defined in the extension area of the house. The tools are rated against each part of the problem breakdown to show if they will help solve that part of the problem. The rating system for this section ranges from 0 to 10 . This range was found to be an optimal range for users to work with. A smaller range did not give results that clearly distinguished between the tools. A larger range became too cumbersome to use and made it difficult for the user to assign appropriate values. A score of 0 shows that the tool does not provide any solution for that part of the problem breakdown, and a score of 10 indicates that the tool will offer a complete solution for that particular part of the problem

Subtotals are calculated for each of the tools or techniques that have been considered. As there is both positive and negative sides to the problem there are two subtotals calculated. These subtotals are calculated by multiplying the rating for each problem part with the IT tool rating relevant to that part of the problem. This is all added up into one positive and one negative subtotal for each tool. For the positive features, the highest score shows the tool that is the most likely to offer the best solution at this stage. The negative subtotal for each tool is calculated in the same way but at this point the highest subtotal is the least desirable.

The Total section only considers the two subtotals that have been calculated. The negative subtotal is subtracted from the positive subtotal and gives an overall result for each tool. These totals can be used to decide which tool offers the best solution for the problem with the highest total showing which tool is the most likely to solve the problem. The subtotals and the individual ratings for each tool give an invaluable breakdown to the manager as to whether the tool will offer a complete solution or only a partial one.

\subsection{The Tool Connections Area (The roof)}

In initial experiments to create the HoKMTS, it was soon found that some tools could not be used independently. An example is a user-rating system. This tool could not be used without anything to rate! However, when used with, say, a discussion forum, the users' ratings of the helpfulness of points made in the discussion can help others to find elements of the discussion that were more likely to be of use in their own situation. It becomes important, therefore, to know which tools can be used together.

The roof section of the house is used, therefore, to show if two tools could be used together to provide a more complete solution to the problem. 


\subsection{Barriers Area (basement)}

The barrier section is positioned in the basement of the house reflecting that although they may be hidden their solution underpins the solving of the problem. The barriers that have been selected to populate the house have been shown to influence the success of knowledge management initiatives. Including them allows the manager to see how issues outside of the knowledge management problem but still within the organisation may influence the successful implementation of the tool. Each barrier will be considered in two parts. The first is to ascertain the influence the barrier has on the success of the tool solving the problem and the second to consider how easy it is to overcome the barrier.

Both of these parts of the barrier are then rated against the tools. The barriers have not been given a numeric value as these are not incorporated into the final total section of the house. Instead they are rated by using a red, amber, green (RAG) system. When this section has been filled in for each tool the manager will be able to see if the barriers for the tool are likely to affect the success of the tool. A lot of red entries suggest that the barriers are a problem and a lot of green entries suggest that the barriers are not an issue. The amber results would show that the barrier will have some effect on the tool.

\section{Case Study}

An initial case study was undertaken to test the tool and check the results that were found in order to further develop the house. A knowledge problem from Loughborough University was selected to test the HoKMTS. The problem definition is "How do people identify and communicate with potential collaborators from different disciplines?" This is a particular problem in some research areas, for example Knowledge Management and Systems Engineering are disciplines that cross many departments within the university.

To start the process of populating the house with the relevant information each section was taken in turn and completed. The first task was to clarify the problem itself and to break it down into components that would fill in the left hand extension or problem requirement area. The requirements would also need rating to show how important they are to solving the problem. The main requirement is for the solution to be able to find people within the University whose research was on a set topic. The search and locate requirement was given a 5 rating. The next requirement is communication and collaboration, and again a 5 rating was given for this, as the problem requires the user to converse with the people that have been located. Both innovation and storage are seen as regular components of knowledge management problems, but in this case they do not feature as requirements so they were given a 0 rating but still included in the house to show tools that could have this extra functionality. Reliability of the tool was also included and given a rating of 4 as any tool needed to offer a reliable solution but this was not considered to be as important as the first two requirements. The requirements above are positive ones as a rating of 5 shows them to be desirable qualities.

The following requirements are all negative ones where a rating of 5 shows them to be undesirable. The first of these is cost in money and a tool with a high rating would suggest that this is an expensive option. Cost in time to the user and the maintenance of the content are also important parts of the problem requirements and are rated accordingly.

To populate the tool section on the top floor, a list of potential tools needs to identified. For this problem an IT solution was sought. The IT tools that have been suggested are those that appear regularly within knowledge management literature, such as document management systems (Kankanhalli et al. 2003) and Web 2.0 technologies, which are becoming increasingly employed in companies (Lynch 2008). Tools being considered include blogs, wikis, RSS feeds and social networks (AIIM International 2008). A selection of tools already available in the University such as e-mail and people pages were also included to see if they could be applied to solve the problem. Whilst filling in this section it was noted that a list or classification of potential knowledge management tools would have been a useful starting point in deciding which tools would be suitable to fill this section of the house, but that no list was found. A general list would have ensured that all possible tools were considered for inclusion in the house with the potential of finding a more innovative tool or one that would not have been previously thought about.

The third section to be completed was the relationships and results section in the main body of the house. Each tool was taken in turn and values between 0 and10 were assigned for each part of the problem.

For video conferencing, it soon became apparent that it would not fulfil many of the requirements. The tool was allocated a score of 0 for the search and locate category due to it 
having no functionality that would help with this. It was given a score of 8 for communication as it would help achieve this as long as it was known who to communicate with. Although given a high score for innovation, this was not required by the problem and therefore did not add to the final subtotal score. The tool was allocated a high value for money and time in the lower part of the relationship and results section and thus it produced a high negative subtotal for this tool. The negative subtotal was taken away from the positive subtotal this left a negative result of -7 , showing that the tool was unlikely to be of value for solving the problem. Similar logical arguments were used to derive the values allocated to the remaining tools in this section. One of the tools was allocated a maximum score of 10 for the search/locate problem requirement, but as this was a tool designed particularly for this purpose this seemed reasonable.

\begin{tabular}{|c|c|c|c|c|c|c|c|c|c|c|}
\hline & & \multicolumn{9}{|c|}{ IT Tool } \\
\hline & & \multirow[t]{2}{*}{$\frac{7}{3}$} & \multirow[t]{2}{*}{$\stackrel{\infty}{0}$} & \multirow[t]{2}{*}{ ô } & \multirow[t]{2}{*}{ 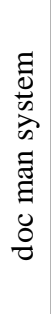 } & \multirow[t]{2}{*}{ 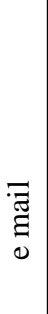 } & \multirow[t]{2}{*}{ 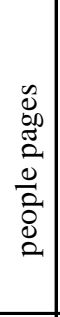 } & \multirow[t]{2}{*}{ 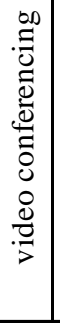 } & \multirow[t]{2}{*}{$\begin{array}{l}\underset{\mathscr{U}}{\mathscr{U}} \\
\underset{\mathscr{N}}{\mathscr{\sim}} \\
\mathscr{\sim}\end{array}$} & \multirow[t]{2}{*}{ 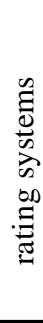 } \\
\hline Problem Requirements & Rating & & & & & & & & & \\
\hline Search/locate & 5 & 2 & 4 & 5 & 5 & 1 & 10 & 0 & & \\
\hline Communication/ collaboration & 5 & 3 & 6 & 8 & 3 & 8 & 5 & 8 & & \\
\hline Innovation & 0 & 6 & 6 & 9 & 2 & 3 & 0 & 7 & & \\
\hline Storage & 0 & 7 & 7 & 3 & 9 & 5 & 5 & 0 & & \\
\hline Reliability & 4 & 7 & 7 & 7 & 4 & 9 & 7 & 5 & & \\
\hline Sub total +ve & & 53 & 78 & 93 & 56 & 81 & 103 & 60 & & \\
\hline Total & & -4 & 19 & 37 & -6 & 48 & 68 & -7 & 0 & 0 \\
\hline Sub total: -ve & & 57 & 59 & 56 & 62 & 33 & 35 & 67 & & \\
\hline Cost $£$ & 4 & 4 & 4 & 4 & 8 & 0 & 2 & 10 & & \\
\hline Cost in time for user & 3 & 7 & 9 & 8 & 2 & 7 & 5 & 9 & & \\
\hline $\begin{array}{l}\text { Maintenance: Content } \\
\text { Management(3rd party) }\end{array}$ & 4 & 5 & 4 & 4 & 6 & 3 & 3 & 0 & & \\
\hline \multicolumn{11}{|l|}{ Barriers } \\
\hline \multirow{2}{*}{ Business case } & Influence & & & & & & & & & \\
\hline & overcome & & & & & & & & & \\
\hline \multirow{2}{*}{ culture } & Influence & & & & & & & & & \\
\hline & overcome & & & & & & & & & \\
\hline \multirow{2}{*}{ incentive for user } & Influence & & & & & & & & & \\
\hline & overcome & & & & & & & & & \\
\hline \multirow{2}{*}{ management support } & Influence & & & & & & & & & \\
\hline & overcome & & & & & & & & & \\
\hline
\end{tabular}

Colour key: $\square($ red) = Major problem, $\square($ yellow $)=$ partial problem, $\square($ green $)=$ not a problem

Figure 3 Case study House of Knowledge Management Tool Selection

The functionality that a tool has built into it could alter the rating it is given, for example, if the people pages had no search facility (e.g. It was just an alphabetical list) it would not be given such a high score the search/locate requirement. While rating the tools it was also found that RSS feeds 
and rating systems did not work independently but would need to be added to another tool to make them work. This enabled the roof section to be populated.

From the totals results it can be seen that people pages offers the best solution with email coming second. The subtotals show that email has a very low negative subtotal in terms of cost due to it already being widely used. When looking at a tool such as a community of practice (COP) it is noted that this had the second highest positive subtotal but due to high costs that overall it only ended up as third in the total section. From this it can be deduced that it is important not to simply look at the totals section but that a manager needs to look at all the scores given to a tool to make an informed choice.

The barrier section in the basement has been populated with four barriers that have been seen to have caused knowledge management initiatives to fail (Du Plessis 2008; Kerno and Steven 2008). The barriers are then given either a red, amber or green colour for the influence that the barrier may have on the success of the tool in question. A second colour based on how hard it is to overcome this barrier is also given for that specific barrier. For the purpose of this paper green is represented by light grey, amber by medium grey and red by dark grey. Looking at that part of the house in Figure 3 it can be seen that for email most of the barriers are green. This is due to the fact that email is widely used in the university and seen as a normal everyday tool. The other tools show more reds in their results with people pages showing that no management support has a strong influence over the tool being successful and that it will be hard to overcome.

\section{Conclusion to the Case Study}

From the case study it can be seen that the HoKMTS has been used to systematically evaluate the potential tools to solve a knowledge management problem. The problem used was a simple one with an obvious outcome. The pilot study has given a proof of concept but more research is necessary to explore the use of the tool in different circumstances and by different users. To achieve this more case studies need to be undertaken.

One area of concern that became apparent as the house was being populated was the lack of a list of knowledge management tools being available to select from for the tools and techniques section of the house. How can a manager find the tools to complete this section of the house? One problem is that the tools that are entered here could be limited to those that are obvious or that the manager has heard of. This narrows down the possibilities of finding an innovative solution to a knowledge problem or to consider if a combination of tools could offer a better solution. A classification of knowledge management tools that could be used to help populate this area would offer the knowledge manager a resource to refer to. This would highlight tools that otherwise would not have been considered as knowledge management tools.

\section{Literature Review of Classification Methods}

The literature was examined to determine whether an existing method of categorising knowledge management could be used by a knowledge manager to help populate the house.

From the literature it was found that there are two main ways to classify tools (Al-Ghassani et al.2002). The first is to investigate knowledge management processes and match tools to the processes. The second is to classify tools according to technology groups. A further development was found to be matching the technology groups to the knowledge management processes.

Classification by knowledge management processes has been approached by various authors who have produced slightly different processes. Ruggles (1997) split knowledge management into generation, codification and transfer and related them to the knowledge management tools. An example of this is Lotus Notes and NetMeeting which are tools that would facilitate knowledge transfer. This pattern was also followed by Wensley (2000) breaking down knowledge management into acquire, store, deploy and add value. He then looked solely at web based tools such as Action Technology Tools and Documentum relating them to the 'add value' stage.

One problem that is apparent is which tools are used in a classification. Using tools that are defined by vendor can mean that the classification becomes dated as the tools become either obsolete or their functionality alters over time to keep up with the demands of the market. This has been bypassed by using generic categories for the tools (Al-Ghassani et al.2002). These generic categories are then matched to the various knowledge management processes. Jackson (1998), for instance, suggests that, for the process of storage, the tools would be 'linking, indexing and filtering'. The communication process involved tools such as 'sharing, collaboration and group decisions'. 
These methods of looking at tools are still not helping a knowledge manager in understanding the value of knowledge management tools to their organisations and does not show enough detail about the tools that are being investigated. It can also be noted at this point that all the tools that have been examined by other authors are IT based tools. There is no consideration given to the non IT tools of knowledge management and yet it is recognised that knowledge management is not just about IT (Mohamed and Mohamed 2008). For example, the Knowledge Cafe (Dvir and Pasher 2004) can be an effective tool for knowledge generation, yet it does not require IT. The knowledge management processes that are being used in these classifications are very broad. The communication process can be approached in different ways such as publishing, face to face and transmission (Tyndale 2002) and tools may only address certain types of communication. This is not reflected in the classifications that have been carried out.

Al-Ghassani et al (2002) suggested that the second method used to classify tools is by technology group and found that these were not matched to knowledge management processes. For example, Gallupe (2001) suggested information retrieval programs and intelligent agents. AlGhassani et al (2002) further suggest that classifying knowledge management tools by the technology group that they are based on is not very useful to an organisation when searching for a method to identify an appropriate tool.

Tyndale (2002), however, also classified tools by technology groups and then matched them to knowledge management activities. Tyndale (2002) suggested sixteen technology groups such as the Intranet and databases, and matched them to four knowledge processes, those being creation, organisation, distribution and application. However, by using technology groups as opposed to specific tools the results from the study by Tyndale (2002) showed that each technology group matched nearly all of the knowledge management activities that had been suggested and from a knowledge manager's point of view were still not specific enough to be of any use.

\subsection{Conclusion to the Literature Review}

From the literature review it can be concluded that a classification or way of examining knowledge management tools that can be used effectively by the knowledge manager or be applied to the house has not been found. The classification of tools that is available from the literature may not always offer the knowledge manager a clear solution as to which tool or technique may be the most suitable for an organisation to employ or even what part of a knowledge management problem it may be capable of addressing. When considering the knowledge management processes that were used, it was found that there were only a few of processes which result in a large number of tools that could applied to them. These knowledge processes could be further split into different types that the classifications did not address.

It was also concluded that the classification of knowledge management tools and techniques is normally limited to IT tools and no author has investigated the non IT options that exist to any great extent, if at all, and the more recent knowledge management tools are often not included. A more useful classification would be one that is flexible, that could be applied to various types of tools and that could be added to easily when new tools and techniques are identified.

\section{The Knowledge Management Problem-Tool Classification Grid}

To provide a useful method for classifying knowledge management tools it was decided to match the knowledge management tools against the knowledge problem. This will give a knowledge manager a categorisation of tools that will allow the manager to understand which tools can address the particular knowledge problem that they are dealing with.

Having not found a definition for the term knowledge problem anywhere it was decided to define a knowledge problem as

'A problem caused by a lack of knowledge in a particular context'.

The knowledge problem was then broken down into several types so that the tools could be matched against a specific knowledge problem that they could help solve.

The final classification is aimed at being flexible so that it can include all types of knowledge management tools that will be classified i.e. both IT and non IT tools, ranging from forums and wikis to rating systems and storytelling. 


\subsection{Knowledge Problem Breakdown}

The initial breakdown of the problem uncovered only six types of knowledge problem. Further brainstorming sessions were undertaken that involved looking at the tools and attempting to place them within the types of problem that had been identified. This highlighted a further four sections that needed to be included as the original list was too limited. Thus ten types have been identified that are regularly seen as part of knowledge management:

1. Source signposting: a form of mapping tool that enables the user to identify where knowledge may be available from.

2. Search

3. Creation / innovation

4. Validation: checking the value of knowledge

5. Storage: A tool that enables the knowledge to be stored so that it can be retrieved and used at a later date.

6. Transfer/ distribution: one way transfer of knowledge

7. Collaboration/sharing: two way transfer of knowledge

8. Tacit to explicit: A tool that allows tacit knowledge to be changed into explicit knowledge

9. Decision making

10. Representation/ analysis

'Source Signposting' and 'Searching' were originally seen as the same as both were used to help find knowledge. On further investigation, the two were made into separate problem types as they were in fact slightly different. 'Source Signposting' requires structure in knowledge and a form of stored knowledge. 'Searching' does not require that structure, is more versatile in finding knowledge and is more likely to find knowledge that is not anticipated in the first place.

'Tacit to Explicit' is seen as means of capturing the knowledge in a person's head so that it may be used by others. Without capture, such knowledge is lost when an employee leaves the company and takes the knowledge they have gained away with them. The tools are used in order to capture that knowledge so that it can be recorded and used again at a later date. This differs from 'Creation/Innovation' which focuses on generating completely new knowledge.

Communication was initially one type of knowledge problem. Through constant updating of the grid, it was recognised that this type of knowledge problem can be divided into two separate types of problem. The first was dealing with tools that offered one way communication and was labelled 'Transfer/Distribution' and the second was with tools that offered two way communications and was labelled 'Collaboration/Sharing'. Although some tools such as email and forums could do both, others such as blogs and RSS feeds could only be used in a one way distribution of knowledge.

\subsection{Matching the Tools to the Problem Type}

The tools are then matched to the part of the knowledge problem they are capable of solving. At this point it was decided that it would be more useful to the knowledge manager if the tools were put into groups for each type of the knowledge problem. Initially this division was decided in terms of how important the tool was to that section of the knowledge problem or how good it was at offering a solution. An attempt was made to order the tools for each problem type according to how much of that particular problem it would solve. A number of grades from "may be helpful" through to "very effective" were tried. However, it was decided that this was too subjective and the order of the tools in this sort of list could vary greatly from one person to the next. A more objective approach that would be of more use to a knowledge manager was to divide the knowledge areas into three levels. These levels are:

1. The main purpose of the tool

2. Added bonus

3. Not a guaranteed outcome

The first is 'the main purpose of the tool'. Many of the tools have been found to have one main purpose that is associated with it, such as a document management system being primarily used for storage, though some tools can be found to have two purposes.

The second section that the tools are divided into is the 'added bonus' section. This section contains the tools that can also address this part of a knowledge problem but that it is not the primary function of the tool, and it may not be as efficient at providing a solution to that particular part of the knowledge problem in all circumstances. The tool would, however, help address this type of knowledge problem whenever it is used but it is not the tool's primary intended purpose. 
The third section that a tool may fall in is 'not a guaranteed outcome' section. This refers to the ability of a tool to sometimes address that part of a knowledge problem but that it will not always be able to do this. An example of this is the coffee machine or room which, because it brings

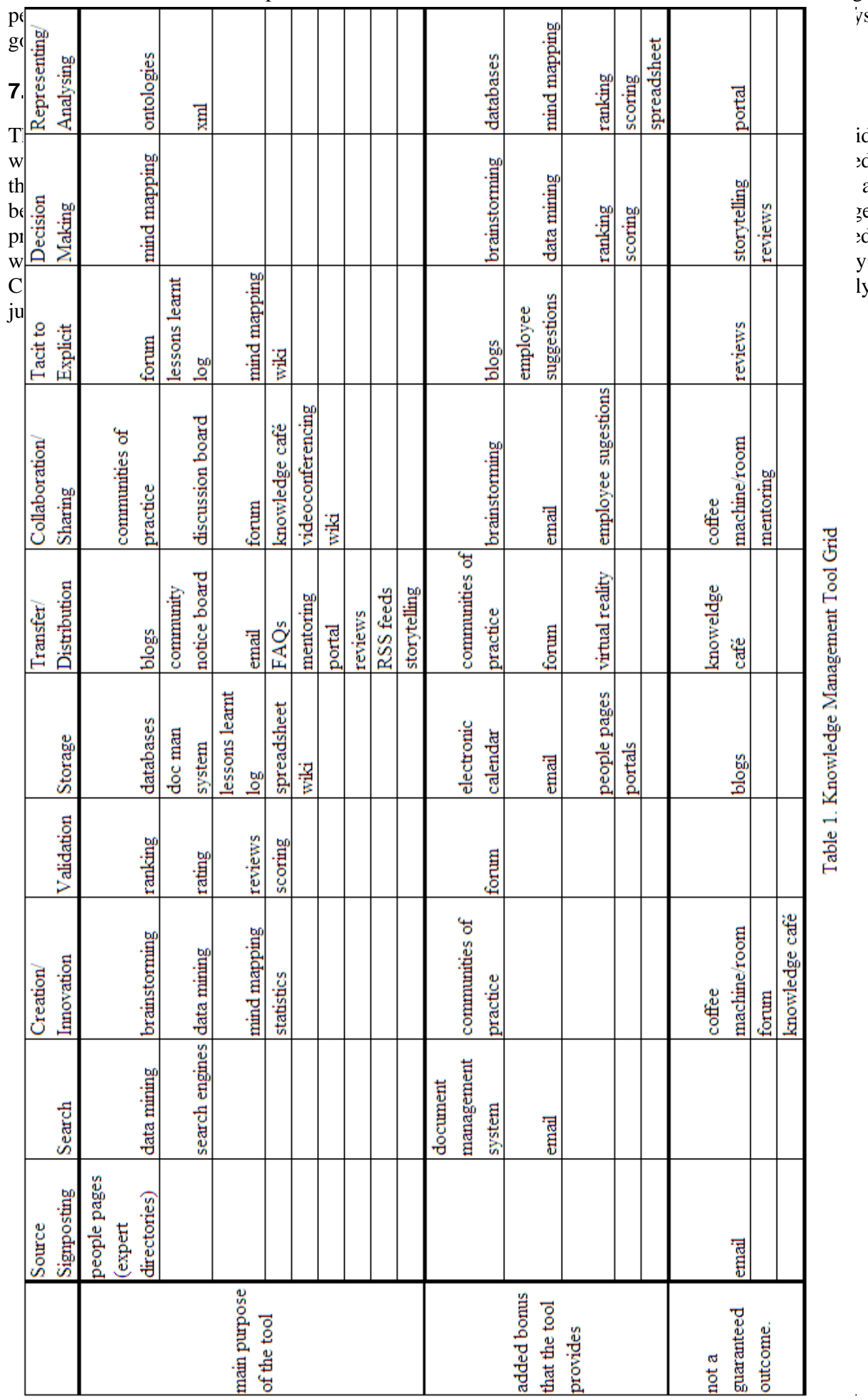


Table 1 shows the completed knowledge management tool grid. The grid was found to be flexible enough to add the non IT tools that are associated with knowledge management. From the completed grid it can be seen that tools such as the 'coffee machine' and 'knowledge café' have been included, both of which are non IT tools.

A tool did not necessarily fit into each of the three levels. For example 'virtual reality' is not found in the 'main purpose of a tool' level but has successfully been used as a KM tool in a case study described by Dawson (2009) where it was a tool for knowledge communication. Virtual reality has been included in the grid as a tool that could be used for the transfer and distribution of knowledge. Although this tool is not normally associated with knowledge management, the grid shows its versatility by being able to include it.

Tools that were added to other categories or changed categories included Wikis. Following a conversation with knowledge workers at Airbus it was realised that they did not use wikis to simply capture knowledge but also to store knowledge. Airbus has found that wikis are becoming an increasingly popular tool due to them being easy to design, low cost and easy to use.

From the analysis of the tools it can be seen that no one tool can be matched to all the different divisions of the knowledge problem when taking into account the three different sections. In fact, except for 'forums', no tool managed to cover half of the knowledge problem types that have been suggested. This suggests that tools will need to be used in combination with each other in order to resolve knowledge deficiencies that involve several types of knowledge problem. Tools that are considered to be knowledge management tools did not appear significantly more often than those that are considered as tools that have leant themselves to knowledge management. For example, email occurs on the grid as often as the knowledge cafe.

Nearly all of the types of knowledge problem have a choice of tools at the top two levels with only two problem types, validation and capture, having no available tools at the 'not guaranteed' level. It was recognised that the tools could potentially be moved to different levels and to different problem types on the grid depending on who was populating it and the organisation that was involved. The grid as created by the authors should, therefore, not be used blindly but an assessment of the tools and categories should be carried out to ensure they are in the correct place for the purpose they are being used for in the context of the organisation where they will be used.

\subsection{Conclusion for the Knowledge Management Problem-Tool Classification Grid}

The knowledge management problem- tool classification grid is an effective way for a knowledge manager to understand the potential of knowledge management tools. It clearly shows which tools are appropriate for each type of knowledge problem and gives the knowledge manager a choice to select from, including IT tools, non IT tools, recent tools and those tools that are not always associated with knowledge management problems. Carefully assigning each tool to the different parts of the grid has been found to give a greater understanding of the nature of the tools in the context where they will be used. It is therefore recommended that managers take the time to create and fill in their own version of the grid rather than taking the populated grid exactly as illustrated in this paper.

Once the grid has been created, it will help in populating the House of Knowledge Management Tool Selection in the area that requires the list of tools, and will also give a better insight and understanding of the knowledge problem requirement section. Used with the house in this way, the proposed knowledge management tool categorisation will assist managers in selecting the most appropriate tool to solve a particular problem within a particular organisation.

The research also suggests the grid could also be used as an evaluation tool for existing knowledge management systems in an organisation, and future research will examine this potential use of the classification system proposed. Further research should also be able to develop and improve the tool such that it could become an essential part of a manager's decision making toolkit.

\section{Overall Conclusion}

This paper has identified two useful tools to assist Knowledge Managers in their decision making processes when deciding which knowledge management tools to implement to address a particular problem in a particular environment. The House of Knowledge Management Tool Selection is a simple graphical tool that can enable managers to evaluate the potential knowledge management tools to solve a particular problem in the context of their company environment. The knowledge 
management problem-tool classification grid helps managers to understand the nature and use of the knowledge management tools in their company context and this, in turn can help them populate the House of Knowledge Management Tool Selection with suitable tools for consideration. The two proposed tools are therefore complimentary.

Both of the tools proposed in this paper have the advantage of being able to handle non IT tools as well as IT tools, and both have the flexibility to be extended or tailored for any particular working environment. The authors therefore suggest that the use of these tools together would assist knowledge managers to increase their understanding of the knowledge management tools they have available and make better considered decisions concerning knowledge management tool deployment. These decisions should, therefore, increase the chances of success for the tools implemented which, in turn, should lead to a better quality knowledge environment.

\section{References}

AIIM International (2008) Enterprise 2.0 Technologies "Critical to Business Success". International Journal of Micrographics \& Optical Technology, 26(1), pp. 6-6.

Al-Ghassani, A., Robinson, H., Carrillo, P. and Anumba, C., (2002). A framework for selecting knowledge management tools, Third European Conference on Knowledge Management. 2002, Academic Conferences Limited pp43.

Dawson, R, (2009), 12 Steps to Successful Knowledge Management Implementation, Proceedings of the 10th European Conference on Knowledge Management, Bolisani and Scarso (Eds.), ACI, European Conference on Knowledge Managment (ECKM2009), Vicenza, Italy, September 2009, pp.209-215, ISBN: 978-1-906638-39-9

Dawson, R.J., (2007). Knowledge Management Implementation Problems and How to Overcome Them, Proceedings of Software Quality Management XV: Improving Quality in Computing Education, Berki, Nummenmmaa, Sunley, Ross and Staples, BCS, Software Quality Management 2007, Stafford, UK, April 2007, pp. 341-352, ISBN: 978-1-902505-96-1.

Du Plessis, M., (2008). What bars organisations from managing knowledge successfully? International Journal of Information Management, 28(4), pp. 285-292.

Dvir, R. Pasher, E. (2004) Innovation engines for knowledge cities: an innovation ecology perspective, Journal of Knowledge Management 8(5), pp. 16-27, ISSN 1367-3270

Gallupe, B., (2001). Knowledge management systems: surveying the landscape. International Journal of Management Reviews, 3(1), 61-77.

Holland, S.J. and Dawson, R.J., (2009). Finding the Right Tool for a Quality Knowledge Management Solution, Proceedings of the Software Quality Management XVII : Software Quality in the 21st Century, Dawson, Ross and Staples, BCS, Software Quality Management XVII (SQM2009), Southampton, UK, April 2009, pp.67-78, ISBN: 978-1-906124-22-9.

Jackson, C., (1998). Process to Product: Creating tools for knowledge management. Knowledge Management for Business Model Innovation, 402-13.

Kankanhalli, A., Tanudidjaja, F., Sutanto, J. and Tan, B.C.Y., (2003). The Role of IT in Successful Knowledge Management Initiatives. Communications of the ACM, 46(9), pp. 69-73.

Kerno, J.,Steven J., (2008). Limitations of Communities of Practice. Journal of Leadership \& Organizational Studies (Sage Publications Inc.), 15(1), pp. 69-78.

Logan G.D and Radcliffe D. F (2007). Potential for Use of a House of Quality Matrix Technique in Rehabilitation Engineering, IEEE Transactions on Rehabilitation Engineering, 5, 1, 105-116.

Lynch, C.G., (2008). Enterprise Web 2.0 Adoption Still GROWING. CIO, 21(23), pp. 17-17.

Mohamed, M.A. and Mohamed, M.S., (2008). Compendious reflections on VINE's technology inquiries. VINE, 38(4), 388-397

QFD Online (2007) QFD Templates http://www.qfdonline.com/templates/ (visited February 2009)

Ruggles, R.L., (1997). Knowledge management tools. Butterworth-Heinemann.

Tyndale, P., (2002). A taxonomy of knowledge management software tools: origins and applications. Evaluation and program planning, 25(2), 183-190. 
_Wensley, A. (2000). Tools for knowledge management. BPRC Conference on Knowledge Management: Concepts and Controversies, 10-11, February 2000, Coventry: University of Warwick 